\title{
Avaliação do modelo J2000/JAMS para modelagem hidrológica em bacias hidrográficas brasileiras
}

\author{
J2000/JAMS model evaluation for \\ Brazilian watersheds hydrological simulation
}

Aline Ribeiro Machado', Arisvaldo Vieira Mello Junior², Edson Cezar Wendland³

口-

\section{RESUMO}

A gestão de recursos hídricos no Brasil é prejudicada pela carência de informações hidrológicas, que pode ser suprida pelos modelos hidrológicos que simulam o comportamento das bacias hidrográficas. Entretanto, muitos modelos não geram bons resultados quando executados fora da área de estudo onde foram criados. Por isso, devido à sua adaptabilidade, o modelo J2000 inserido no framework Jena Adaptable Modelling System (JAMS) foi avaliado para simulação de duas bacias hidrográficas inseridas na zona de afloramento do Sistema Aquífero Guarani, a Bacia Hidrográfica do Ribeirão da Onça (BRO) e a Microbacia do Córrego Cavalheiro (BCC), nos municípios de Brotas e Analândia, respectivamente, no estado de São Paulo. O framework JAMS apresentou-se como um sistema simplificado para uso, flexível diante das adaptações necessárias para compatibilização com as características climatológicas e hidrológicas das áreas de estudo. O modelo J2000 mostrouse eficiente na predição da resposta hidrológica das bacias hidrográficas, apresentando um coeficiente de Nash-Sutcliffe (NSE) de 0,76 e 0,81, para os períodos de calibração e validação da BRO; e 0,76 e 0,56, para os períodos de calibração e validação da BCC, respectivamente. Oerro absoluto, calculado pelo valor da raiz do erro quadrático médio, foi considerado baixo por apresentar valores de 0,14 e 0,18 $\mathrm{m}^{3} \cdot \mathrm{s}^{-1}$ para os períodos de calibração e validação da BRO; e 0,02 e 0,03 m³ $\mathrm{s}^{-1}$ para os períodos de calibração e validação da BCC, respectivamente. Portanto, o J2000/JAMS mostrou-se como um candidato potencial para modelagem hidrológica de bacias hidrográficas do estado de São Paulo, podendo ser utilizado para estudos sobre as relações entre a localização do uso do solo na bacia hidrográfica e a geração de escoamento.

Palavras-chave: série histórica; escoamento superficial; modelagem chuva-vazão.

\begin{abstract}
The water resources management in Brazil is affected by the lack of hydrological information, which can be filled by hydrological models that simulate the behavior of watersheds. However, it was noticed that many models do not generate good results when performed outside of the study area where they were created. Therefore, due to its adaptability, the $\mathrm{J} 2000$ model linked into the Jena Adaptable Modelling System (JAMS) framework was evaluated for simulating two basins at the outcrop zone of the Guarani Aquifer System, the Ribeirão da Onça watershed (BRO) and the Córrego Cavalheiro watershed (BCC), located at Brotas and Analândia cities, respectively, in the state of São Paulo, Brazil. The JAMS framework was presented as a flexible and easy to use system, admitting all the necessary adaptations for compliance with the climatological and hydrological characteristics of the study areas. The $\mathbf{2} 2000$ model proved to be effective in predicting the hydrological response of watersheds, with a Nash-Sutcliffe coefficient of 0.76 and 0.81 , for periods of calibration and validation of the BRO; and 0.76 and 0.56 , for periods of calibration and validation of the $\mathrm{BCC}$, respectively. The absolute error, calculated with the root of mean square error value, was considered low by the present values of 0.14 and $0.18 \mathrm{~m}^{3} \cdot \mathrm{s}^{-1}$, for periods of calibration and validation of the BRO; and 0.02 and $0.03 \mathrm{~m}^{3} \mathrm{~s}^{4}$, for periods of calibration and validation of the BCC, respectively. Therefore, the J2000/JAMS showed up as a potential candidate for hydrological modeling of watersheds in São Paulo, and may be used for studies on the relationship between the location of land use in the watershed and the generation flow.
\end{abstract}

Keywords: historical data; runoff; rainfall-runoff modeling.

\footnotetext{
1Doutoranda em Engenharia Civil-Hidráulica pela Escola Politécnica da Universidade de São Paulo (USP). Pesquisadora do Instituto de Pesquisas Tecnológicas do Estado de São Paulo (IPT) - São Paulo (SP), Brasil.

${ }^{2}$ Doutor em Engenharia Civil (Engenharia de Recursos Hídricos) pela Escola Politécnica da USP. Professor do Departamento de Engenharia Hidráulica e Ambiental da Escola Politécnica da USP - São Paulo (SP), Brasil.

${ }^{3}$ Doutor em Engenharia Civil pela Ruhr Universität Bochum, Alemanha. Professor titular do Departamento de Hidráulica e Saneamento da USP - São Paulo (SP), Brasil. Endereço para correspondência: Aline da Silva Ribeiro - Avenida Professor Almeida Prado, 532 - Cidade Universitária/Butantã - O5508-901 - São Paulo (SP), Brasil E-mail: asribeiro@ipt.br

Recebido: 22/01/15 - Aceito: 2O/06/16 - Reg. ABES: 145177
} 


\section{INTRODUÇÃO}

O homem constantemente altera os mecanismos naturais do ambiente que controlam o ciclo da água. Entre os componentes do ciclo hidrológico, a vazão representa uma síntese complexa entre precipitação, evapotranspiração e outros parâmetros e variáveis da bacia hidrográfica, sendo, portanto, de interesse especial por ser a resposta do rio aos sinais climáticos e à modificação da paisagem — desmatamento, expansão da agricultura e urbanização.

A redução da cobertura vegetal original do solo em uma bacia hidrográfica gera aumento do escoamento superficial e da erosão (CAWSON et al., 2012). A perda de áreas florestais reduz a rugosidade da superfície, o que leva a um declínio na infiltração, com consequente aumento da taxa de escoamento superficial e menor recarga dos aquíferos regionais (BAKER \& MILLER, 2013). A Lei no 9.433, de 1997, instituiu a bacia hidrográfica como a unidade territorial para implementação da Política Nacional de Recursos Hídricos e atuação do Sistema Nacional de Gerenciamento de Recursos Hídricos (BRASIL, 1997), tornando-a uma unidade de planejamento, uma vez que as mudanças no clima e no uso do solo afetam diretamente o ciclo hidrológico de uma bacia hidrográfica (WOLF; LAZAROTTO; BUGMANN, 2012). Portanto, a bacia hidrográfica deve ser considerada como unidade de planejamento para estabelecimento de estratégias para a conservação da água (FERRAZ; LIMA; RODRIGUES, 2013).

Para controlar os impactos das alterações no comportamento do escoamento superficial, é fundamental conhecer as variáveis hidrológicas de uma bacia hidrográfica, bem como o comportamento de seus rios, suas sazonalidades e vazões. No entanto, apenas $17 \%$ dos rios brasileiros estão cadastrados no Sistema Nacional de Informações de Recursos Hídricos, justificando-se o interesse pelo desenvolvimento de métodos e ferramentas que auxiliem a gestão das águas.

Os modelos hidrológicos surgiram como uma tentativa de suprir dados hidrológicos indisponíveis e/ou complementar os existentes, da maneira mais representativa e aproximada da dinâmica real de uma bacia hidrográfica (TUCCI, 2001). São desenvolvidos com o intuito de responder às questões decorrentes de cada época, dando ênfase aos processos hidrológicos mais representativos de cada região, gerando diferentes configurações. O número de combinações possíveis para diferentes métodos em cada componente do ciclo hidrológico é extenso. Por isso, cada pesquisador tende a escolher o modelo que apresente melhores resultados nas bacias da região avaliada, por meio de comparações de eficiências. Esse tipo de escolha não é definitivo, uma vez que as incertezas nos processos e as dúvidas na representatividade dos dados são maiores do que as diferenças entre as equações utilizadas. Por isso, a escolha de um modelo que utiliza métodos mais familiares ou compatíveis com a região estudada é a opção mais apropriada.

O grande desafio para a hidrologia em geral é a necessidade de adaptação dos modelos hidrológicos segundo a singularidade de uma bacia hidrográfica em relação ao seu comportamento hidrológico e à disponibilidade de dados da área (FENICIA; McDONELL; SAVENIJE, 2008). Os modelos hidrológicos codificam um conjunto de pressupostos que podem ou não ser válidos em diferentes momentos, locais, escalas e propósitos (ANDREWS et al., 2011). Portanto, é importante a criação de ferramentas que auxiliem aos hidrólogos na construção de estruturas adequadas para a modelagem hidrológica. Daí a importância do desenvolvimento de um framework que divida as rotinas sistemáticas, necessárias a todos os modelos, da parte científica, requerida pelos pesquisadores e gestores, possibilitando a exploração de benefícios e características particulares dos modelos (KRAFT et al., 2011). Além disso, o framework atua onde há funcionalidades comuns a várias aplicações e auxilia na junção de modelos com diferentes objetivos de simulação seguindo a tendência atual de desenvolvimento de modelos climáticos, hidrológicos e ambientais acoplados.

Por isso, o maior benefício do uso de frameworks é permitir que os desenvolvedores de modelos concentrem-se na implementação de métodos mais adequados, facilitada por uma interface familiar em ambiente de modelagem. Com esse intuito, o framework Jena Adaptable Modelling System (JAMS) foi desenvolvido para contemplar as diferentes partes do ciclo da água - evapotranspiração, interceptação, água-solo, águas subterrâneas - como módulos de processos hidrológicos. Dispõe ainda de módulos para análise da distribuição de soluto e do transporte de sedimento ao longo de uma bacia hidrográfica em diferentes escalas de espaço-tempo (KRAUSE et al., 2009; KRALISCH; ZANDER; KRAUSE, 2009).

Os modelos JAMS são criados a partir de documentos com extensão .xml (eXtensible Markup Language). Esses documentos contêm a descrição dos módulos de processos hidrológicos, que serão utilizados para a simulação, além de definirem a montagem dos componentes do modelo e os dados a serem trocados entre eles. Isso é realizado por meio da interface gráfica Juice Builder. A configuração e a execução do modelo, bem como a comunicação entre seus componentes, são estabelecidas pelo sistema de execução. Esse sistema, com a biblioteca de funcionalidades básicas, como os mecanismos de entrada e a saída de dados, forma o núcleo do JAMS, o qual não pode ser modificado durante a construção de novos modelos, "chamado de parte não conhecida”.

Alguns modelos já foram criados no JAMS para diferentes aplicações. Entre eles, destacam-se os modelos hidrológicos (J2000 e J2000-g) e o modelo de balanço de água e nutrientes (J2000-S). O framework JAMS tem código aberto e possui interface amigável para modificações, o Juice Builder. Também conta com uma interface gráfica, o JAMS Data Explorer (JADE), para a visualização dos resultados da simulação, gerando gráficos de vazão, precipitação, evapotranspiração e umidade do solo versus tempo, o que ajuda o usuário durante a calibração manual dos parâmetros do modelo. 
A estrutura base do modelo J2000 foi utilizada para a construção dos modelos hidrológicos deste estudo. Muitos estudos foram realizados utilizando o modelo J2000 para responder a várias questões em diferentes partes do mundo. O modelo foi aplicado em diversas bacias hidrográficas da Alemanha (KRAUSE, 2002; KRAUSE \& FLÜGEL, 2005; KRAUSE et al., 2006; KRAUSE \& HANISCH, 2009), da África do Sul (SCHEFFLER; FLÜGEL; KRAUSE, 2005), do Tibete (KRAUSE; BOYLE; BÄSEL, 2005), do Nepal (NEPAL et al., 2014), da Jordânia (RÖDIGER; SIEBERT; KRAUSE, 2008), da Tasmânia (BENDE-MICHL et al., 2007) e do Brasil (MACHADO; WENDLAND; KRAUSE, 2016).

A partir das dificuldades e restrições de uso de alguns modelos chuva-vazão com disponibilidade livre no Brasil, este trabalho avaliou o uso do J2000, um modelo hidrológico inserido no framework JAMS, de uso gratuito, para a construção de modelos hidrológicos para estudos de disponibilidade hídrica em bacias hidrográficas; e a relação entre a localização das classes de uso e ocupação do solo e a geração de escoamento. O modelo foi testado perante os dados da Bacia Hidrográfica do Ribeirão da Onça (BRO), Brotas, e da Microbacia do Córrego Cavalheiro (BCC), Analândia, ambas localizadas no Estado de São Paulo, na zona de afloramento do Sistema Aquífero Guarani (SAG), o maior sistema aquífero transfronteiriço da América Latina.

\section{METODOLOGIA}

\section{Áreas de estudo e dados hidrológicos}

Foram selecionadas para este estudo duas bacias hidrográficas inseridas na zona de afloramento do SAG. Uma delas, BRO, possui disponibilidade de dados adequados (espacial e temporalmente), por ser área piloto de estudos do grupo de pesquisas do Laboratório de Hidráulica Computacional (LHC) da Escola de Engenharia de São Carlos (EESC) da Universidade de São Paulo (USP). Já a outra bacia hidrográfica selecionada, a BCC, não dispõe de estação fluviométrica para medição de vazão, como a grande maioria das bacias hidrográficas brasileiras, tendo sido necessário o uso de equações de regionalização de vazão com dados obtidos na estação fluviométrica do Departamento de Águas e Energia Elétrica (DAEE), localizada na Bacia Hidrográfica do Rio Corumbataí, vizinha à área de estudo. O método utilizado para a regionalização será descrito a seguir.

A BRO localiza-se no município de Brotas, ao centro-leste do Estado de São Paulo, entre os paralelos $22^{\circ} 10^{\prime}$ e $22^{\circ} 15^{\prime}$ de latitude sul e entre os meridianos $47^{\circ} 55^{\prime}$ e $48^{\circ} 00^{\prime}$ de longitude oeste, com área de $65 \mathrm{~km}^{2}$. A BCC localiza-se no município de Analândia, também no Estado de São Paulo, entre os paralelos $22^{\circ} 05^{\prime}$ e $22^{\circ} 08^{\prime}$ de latitude sul e entre os meridianos 47³9' e 47²4' de longitude oeste, com 9,9 km² (Figura 1).

Segundo a classificação de Köppen, as áreas possuem clima subtropical úmido com chuvas de verão, apresentando variação para clima tropical úmido com inverno seco. A precipitação média anual da região varia de 1.300 a $1.400 \mathrm{~mm}$. A cobertura da $\mathrm{BRO}$ é formada por um sedimento superficial encontrado em grande parte do interior do Estado de São Paulo, denominado Sedimento Cenozoico, caracterizado por ser pouco compacto, com partículas razoavelmente selecionadas, proporcionando uma estrutura bastante porosa à bacia (WENDLAND; BARRETO; GOMES, 2007). A BCC situa-se na unidade geológica da Bacia Sedimentar do Paraná, pacote vulcânico sedimentar que possui características litoestruturais que proporcionam a formação de três compartimentos geomorfológicos do Estado de São Paulo: Depressão Periférica, Cuestas Areníticas-Basálticas e Planalto Ocidental (IPT, 1981).

A altitude da BRO varia entre 640 e $840 \mathrm{~m}$. O terreno é predominantemente plano com uma declividade média de 7,6 m.km ${ }^{-1}(<1 \%)$, e a extensão do curso d'água principal é de $16 \mathrm{~km}$. A BCC tem um relevo bastante acidentado na porção centro-norte, enquanto na porção centro-sul da bacia ocorre um relevo aplainado, onde se desenvolvem as atividades agrossilvopastoris (SILVA, 2012).

A cobertura do solo da BRO é essencialmente rural com estradas de chão. O principal uso do solo é a silvicultura, cobrindo uma área de $35 \%$ da bacia, seguido por solo exposto (17\%), plantio de citros (15\%), pastagem (7\%), mata (10\%), plantio de soja (5\%) e plantio de cana-de-açúcar (11\%) (Figura 2) (TANIKAWA \& MANZIONE, 2010). O uso do solo preponderante na BCC é a pastagem, recobrindo $31 \%$ da área da bacia, seguido por mata (25\%), plantio de cana-de-açúcar (20\%), área urbanizada (10\%) e silvicultura (11\%), segundo cálculos realizados a partir do mapeamento realizado por Silva (2012) (Figura 3).

Os dados climatológicos (radiação solar, temperatura do ar, umidade do ar, velocidade dos ventos, pressão atmosférica e precipitação) para a construção do modelo da BRO foram disponibilizados pelo Centro de Recursos Hídricos e Ecologia Aplicada (CRHEA), que se localiza a $7 \mathrm{~km}$ do centro da BRO.

Além dos dados climatológicos disponibilizados pelo CRHEA, os dados da estação climatológica do Centro de Análise e Planejamento Ambiental (CEAPLA), da Universidade Estadual Paulista "Júlio de Mesquita Filho" (Unesp) de Rio Claro, São Paulo, foram utilizados para a construção do modelo na BCC.

\section{Análise da estrutura do sistema framework JAMS}

Por não existir um tutorial específico para o framework JAMS, foi realizado um levantamento bibliográfico sobre suas funcionalidades e foram fornecidos exemplos de sua aplicação. Os materiais com maiores níveis de detalhamento sobre o JAMS foram encontrados no site da Universidade Friedrich Schiller de Jena, Alemanha, escritos e/ou disponibilizados pelo criador do framework, o Professor Dr. Peter Krause. São disponibilizados, ainda, materiais com exemplos de aplicações no site criado para a divulgação desse sistema framework (http://jams.uni-jena.de/). Essa investigação 
detalhada foi fundamental para a pesquisa, pois as informações sobre os equacionamentos dos processos simulados, da estrutura dos modelos e dos resultados obtidos com as simulações foram relevantes durante a análise dos cálculos dos processos e para a escolha dos módulos a serem utilizados na construção do modelo para a BRO. Para complementar as informações obtidas com a revisão bibliográfica, foi realizado um estágio na Universidade Friedrich Schiller de Jena, sob a orientação do Prof. Dr. Peter Krause, fundamental para a construção dos modelos hidrológicos para as duas áreas de estudo.

\section{Abordagem da modelagem no J2000}

O modelo J2000 abrange módulos de regionalização de dados climáticos, estimativa da evapotranspiração potencial e real, intercepção, balanço volumétrico de água no solo, balanço volumétrico de águas subterrâneas e propagação do escoamento nos canais (Figura 4).
O módulo de água no solo é a parte central do ciclo hidrológico no modelo J2000. Esse módulo atua como um regulador do sistema de distribuição do volume de água para quase todos os processos hidrológicos no modelo (KRAUSE, 2002). O solo, nesse módulo, é dividido em dois armazenamentos: poros grandes (LPS) e poros médios (MPS). Essa divisão é realizada de acordo com a descrição dos perfis de solos (parâmetros) e a profundidade de raízes de cada uso do solo (ASCOUGH et al., 2012). Assim, o MPS corresponde à capacidade de campo do solo na zona de raízes e o LPS corresponde à capacidade de ar do solo. O MPS só é computado na zona de raízes pelo fato de esse armazenamento só poder ser esgotado pela evapotranspiração.

O cálculo de evapotranspiração potencial no J2000 é realizado utilizando o método de Penman-Monteith, tal como descrito por Allen et al. (1998). Vários parâmetros de uso do solo são necessários para o cálculo de Penman-Monteith (albedo, resistência superficial para solo saturado, índice de área foliar, crescimento

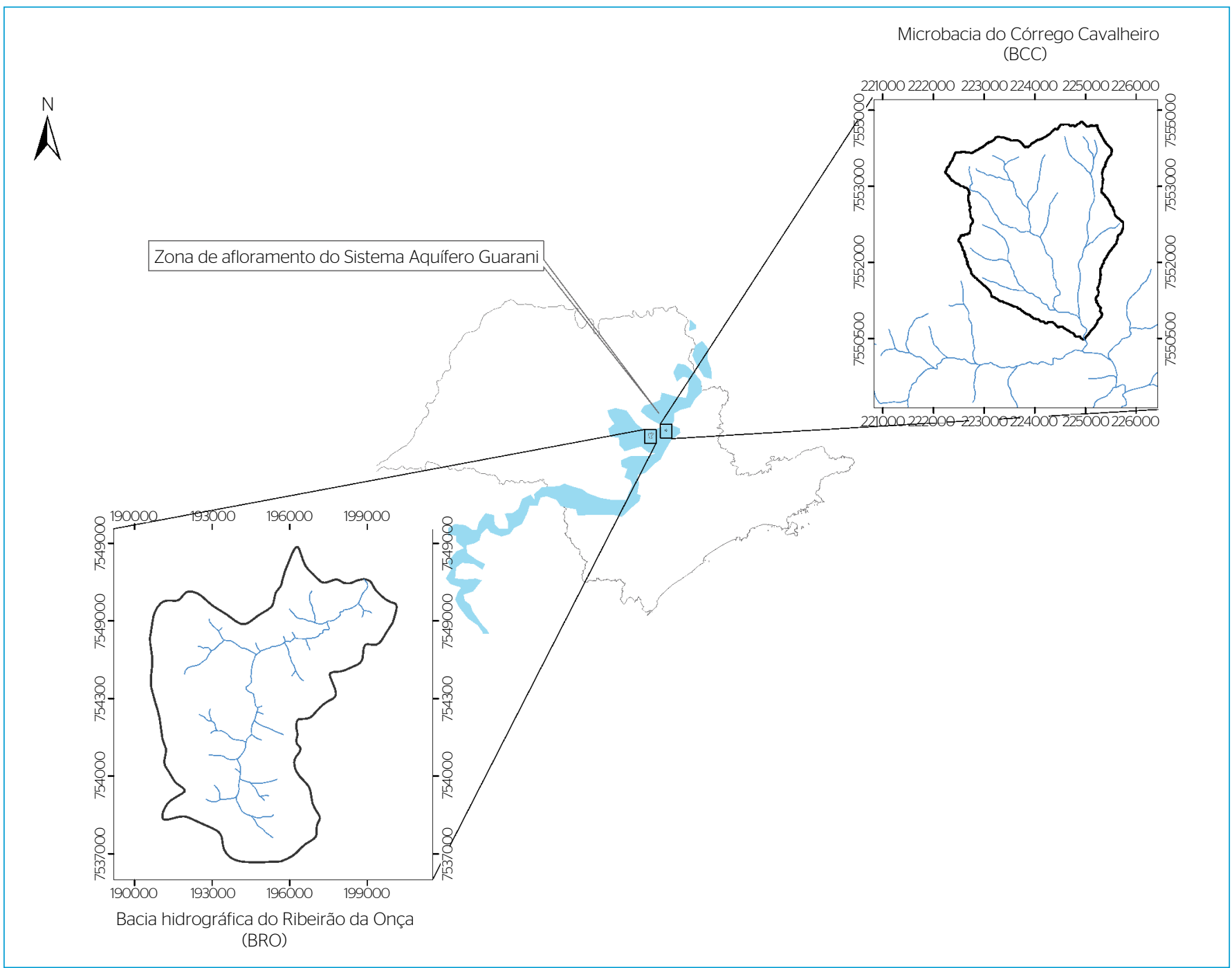

Figura 1 - Localização das áreas de estudo: bacia piloto do Ribeirão da Onça, Brotas, São Paulo, e microbacia do Córrego Cavalheiro, Analândia, São Paulo. 
efetivo da vegetação e profundidade da raiz) e para a estimativa de intercepção (índice de área foliar). Todos esses parâmetros foram obtidos a partir da literatura brasileira especializada para cada uso do solo observado nas áreas de estudo. A estimativa de intercepção é obtida pela multiplicação do índice de área foliar (IAF), de cada uso do solo, com o parâmetro calibrável $\alpha$-rain (capacidade máxima de armazenamento de intercepção por $\mathrm{m}^{2}$ de área foliar para a chuva).

O cálculo da interceptação da precipitação pela cobertura vegetal baseia-se no conceito de Dickinson (1984), que trata a interceptação como um armazenamento dependente do IAF da cobertura vegetal. A capacidade máxima de armazenamento (Intmáx) é então calculada pela Equação 1.

Intmáx $=\alpha . I A F \quad[\mathrm{~mm}]$

onde:

$\alpha$ é um fator que descreve a capacidade de armazenamento por $\mathrm{m}^{2} \mathrm{de}$ área foliar em mm;

IAF é o índice de área foliar

A água da precipitação que não foi interceptada pela cobertura vegetal, somada ao volume de água armazenada na superfície do solo, é infiltrada e distribuída nos dois armazenamentos do solo (LPS e MPS).

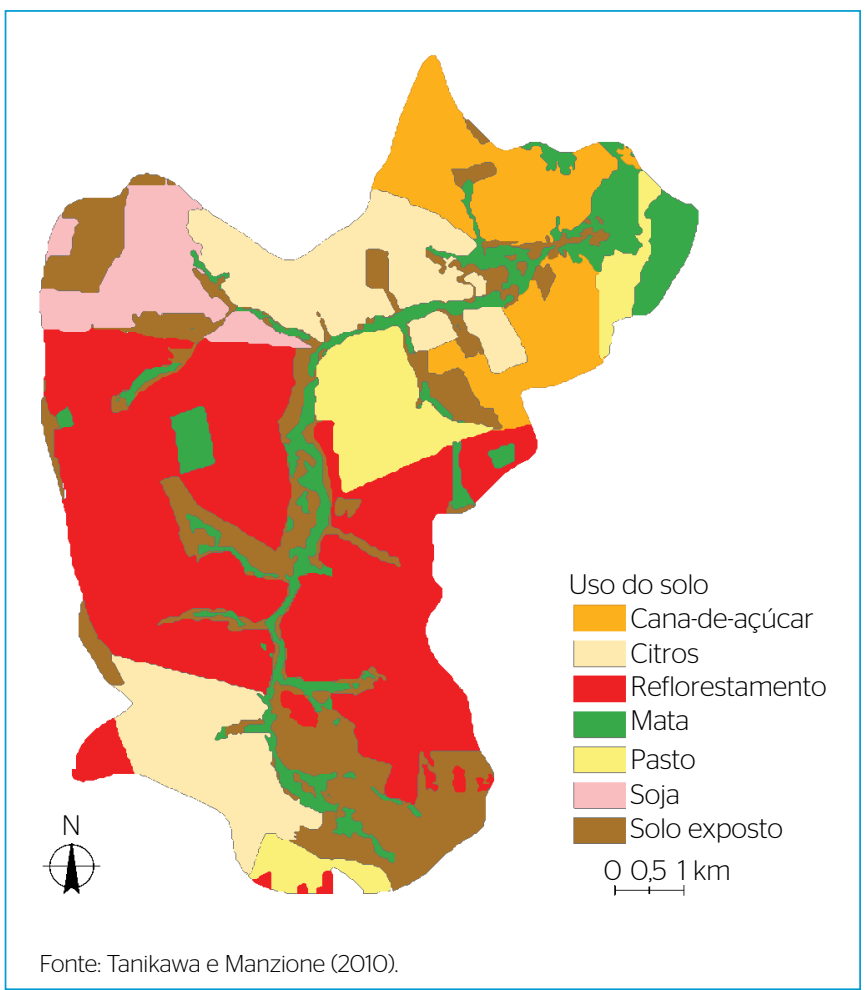

Figura 2 - Distribuição espacial do uso e ocupação do solo na bacia hidrográfica do Ribeirão da Onça.
A taxa de infiltração é calculada usando um método empírico que estima a taxa máxima de infiltração (adaptada dependendo da umidade real do solo) (Equação 2).

$\operatorname{Inf}_{\text {actual }}=\left(1-\theta_{\text {soil }}\right) \cdot \operatorname{MaxInf} f_{\text {summer,winter }}[\mathrm{mm}]$

onde:

Infactual é a infiltração para um determinado passo de tempo em uma unidade de resposta hidrológica (URH);

$\theta \_$soil é a saturação relativa do solo; $\mathrm{e}$

MaxInf $_{\text {summer,winter }}$ é um parâmetro definido pelo usuário que representa o volume máximo de infiltração para um solo seco, sendo que o usuário tem que definir dois valores para o MaxInf summer,winter $_{\text {, um para }}$ o verão e outro para o inverno.

A água que sai do LPS (LPSout) é dividida entre percolação e interfluxo, dependendo da declividade da URH e de um coeficiente calibrável (latVertLPS) para a distribuição da água que sai do LPS em escoamento lateral (interfluxo) ou vertical (percolação), conforme as Equações 3 e 4:

percolação $=$ LPSout.$[1-\tan ($ declividade $)$. latVertLPS $\mid[\mathrm{mm}]$

interfluxo $=1-$ perc $\quad[\mathrm{mm}]$

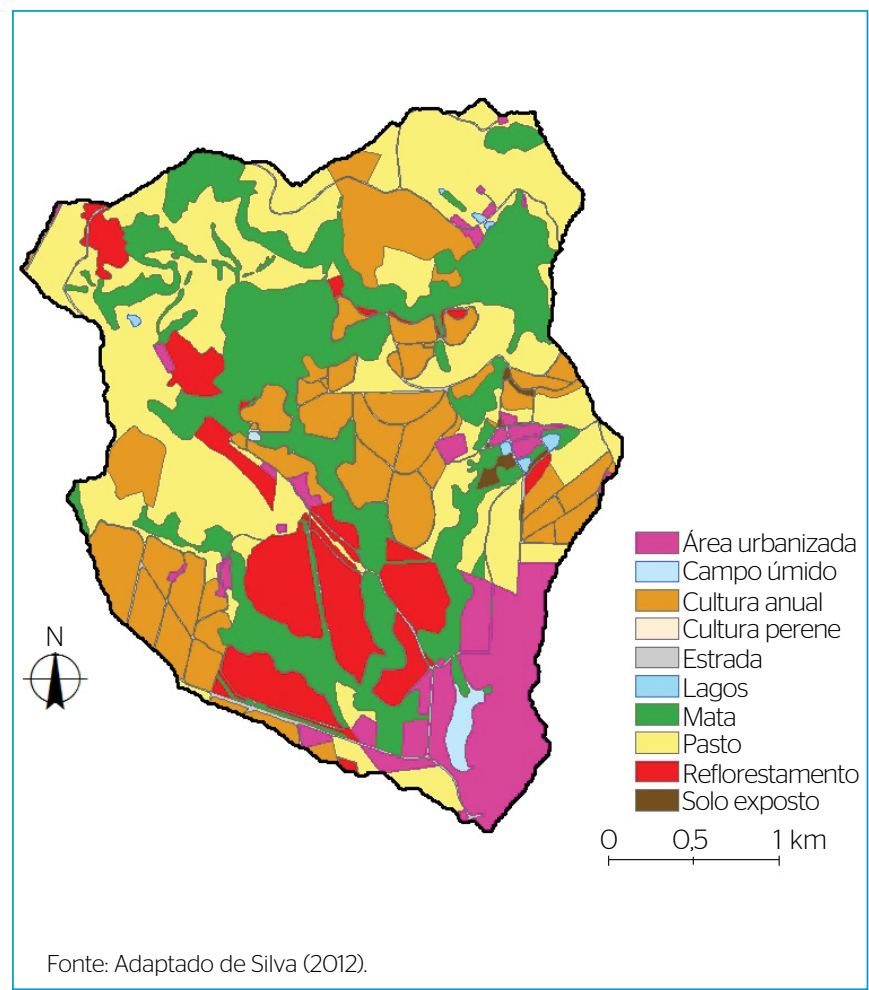

Figura 3 - Distribuição espacial do uso e ocupação do solo na microbacia do Córrego Cavalheiro. 
A percolação é dividida entre os aquíferos RG1 (aquífero superior) e RG2 (zona inferior), dependendo da declividade e de um parâmetro calibrável para a distribuição da percolação entre os dois armazenamentos (RG1RG2dist), seguindo as Equações 5 e 6 :

$i n_{R G 1}=$ percolação. $[1-(1-\tan ($ declividade $))] \cdot R G 1 R G 2$ dist

$\operatorname{in}_{R G 2}=$ percolação. $[1-\tan ($ declividade $)] \cdot R G 1 R G 2$ dist

Onde:

inR $_{\mathrm{G} 1}$ é o volume de água que entra no aquífero RG1 (aquífero superior); percolação é o volume percolado calculado pela Equação 3; RG1RG2dist é um coeficiente calibrável para a distribuição da percolação entre os dois aquíferos (RG1 e RG2); $i n_{R G 2}$ é o volume de água que entra no aquífero RG2 (zona inferior).
Após completado o processo de geração do escoamento, o modelo de propagação da vazão é utilizado para determinar se o receptor é uma outra URH ou um trecho do curso d'água, baseado nas interconexões topológicas derivadas das análises em Sistema de Informações Geográficas (SIG). Assim, o módulo repassa o fluxo de água para a URH em um nível mais abaixo ou para o curso d'água. O fluxo no canal é propagado utilizando-se a abordagem da onda cinemática e a equação de Manning-Strickler para o cálculo da velocidade de fluxo. Mais detalhes e descrições dos módulos do J2000 podem ser encontrados em Krause (2002).

\section{Reestruturação J2000 e construção de modelo chuva-vazão}

Dentre os modelos JAMS, o J2000 foi escolhido para o presente estudo por se tratar de um modelo hidrológico chuva-vazão. Porém, para a

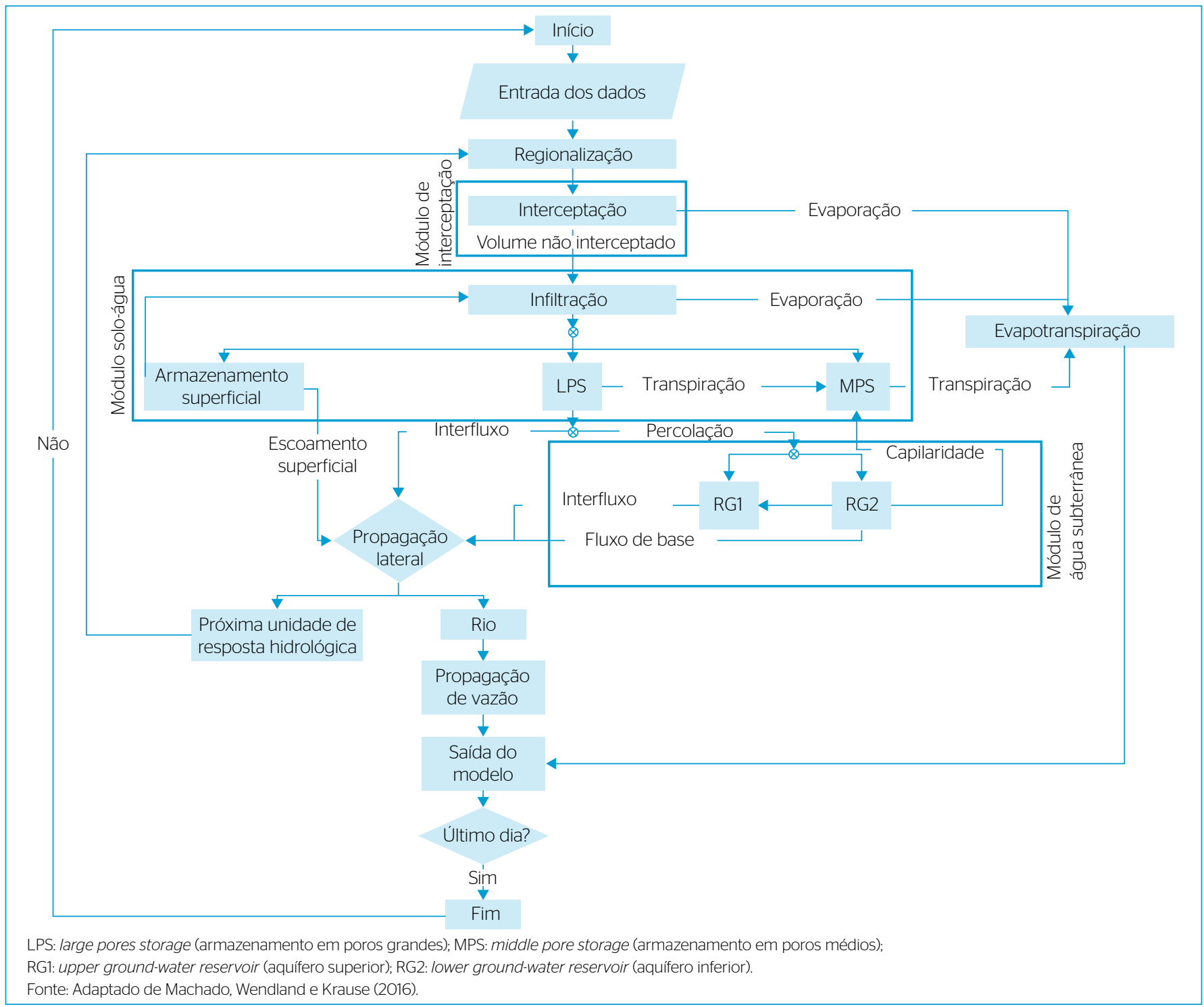

Figura 4 - Esboço da estrutura do modelo chuva-vazão J2000 no framework JAMS. 
aplicação do J2000 em bacias hidrográficas brasileiras foi necessária uma adaptação dos seus módulos originais, principalmente devido às diferenças entre as características climáticas e de natureza dos dados hidrológicos sul-americanos e europeus. A reestruturação do J2000 foi realizada utilizando-se o Juice Builder, uma interface do JAMS para a criação de arquivos XML que definem a estrutura dos modelos.

A primeira manipulação na estrutura do J2000 foi a retirada do módulo que fazia a correção dos erros sistemáticos das medições da precipitação por radar, uma vez que na bacia piloto essas medições são realizadas por pluviômetros. Segundo Silva, Pereira Filho e Hallak (2009), a medição por radar gera erros consideráveis para a simulação devido à grande sensibilidade desse sistema a vários fatores físicos e, por isso, esse módulo de correção foi utilizado para os dados pluviométricos da Alemanha. Foi inserido, ainda, um módulo para o cálculo da umidade absoluta, variável necessária para estimativa do fluxo de radiação na bacia, já que no CRHEA e CEAPLA são coletados apenas valores de umidade relativa do ar. Por fim, por não haver formação de neve no Brasil, os módulos que faziam a simulação do processo de derretimento da neve foram retirados.

Após essa reestruturação, os modelos chuva-vazão foram construídos para serem aplicados nas duas áreas de estudo. Para a construção, seguiram-se as etapas de discretização das bacias hidrográficas com o delineamento das URHs, a parametrização das propriedades físicas do solo, o uso do solo, a hidrogeologia e, por fim, a calibração e validação dos modelos com base nos dados observados nas áreas de estudo.

\section{Delineamento das unidades de resposta hidrológica e da propagação de fluxo}

Neste estudo, os limites das bacias hidrográficas, a rede fluvial, as URHs e as conexões entre os fluxos, referentes à topologia do terreno, foram delineados no aplicativo GRASS-HRU do SIG QuantumGIS. O delineamento das URHs foi baseado em layers do SIG, derivados de um modelo digital de elevação (MDE) com resolução espacial de 90 × 90 m (imagens SRTM) para a BRO e um MDE elaborado a partir das curvas de nível apresentadas nas cartas topográficas do Instituto Geográfico e Cartográfico do Estado de São Paulo (IGC), com escala 1:10.000 e distância entre cotas de $5 \mathrm{~m}$, vetorizadas por Silva (2012) para a BCC; foram também utilizados mapas digitais da geologia (PERROTTA et al., 2005; PINTON, 2011), mapas digitais do uso e ocupação do solo, de 2010 para a BRO (TANIKAWA \& MANZIONE, 2010) e de 2012 para a BCC (SILVA, 2012), e mapas digitais de solo (CASTRO JUNIOR \& WENDLAND, 2008; SILVA, 2012).

Durante o delineamento das URHs, os parâmetros topográficos dos MDE (declividade, orientação de vertente e altitude) foram utilizados para gerar os limites das bacias hidrográficas, e depois foram reclassificados e combinados com os outros layers do SIG (geologia, uso do solo e tipos de solo), por meio da técnica de sobreposição de mapas.
Os polígonos resultantes foram agregados, com base em técnicas de generalização (conjunto de atributos e proximidade da vizinhança), para redução do número global de URHs.

Após o delineamento das URHs, o aplicativo GRASS-HRU reproduziu o fluxo de água em um fluxo de cascata de URH para URH, da área mais alta das bacias até o canal receptor. A relação de transferência entre URHs é uma relação de N:1, assim, uma URH pode ter várias entradas de água, mas apenas uma saída. A discretização da BRO resultou em 449 URHs, enquanto na BCC foram geradas 593 URHs.

Apesar de a área da BCC ser sete vezes menor do que a área da $\mathrm{BRO}$, a discretização gerou maior número de URHs devido a melhor resolução do MDE, gerado a partir das curvas de nível de $5 \mathrm{~m}$. A discretização por meio de URH garante a simulação da variabilidade espacial dos processos hidrológicos das bacias hidrográficas.

\section{Parametrização}

Por ser um modelo físico, alguns parâmetros são exigidos para caracterização das propriedades físicas da bacia como dados de entrada. Na Tabela 1 são mostrados os parâmetros demandados para a caracterização de cada tipo de solo, da cobertura vegetal e da hidrogeologia. Por ser uma bacia hidrográfica experimental, na BRO os parâmetros de caracterização do solo e hidrogeologia foram obtidos de trabalhos realizados anteriormente na bacia para caracterização do solo e da hidrogeologia (GOMES, 2008; CUNHA, 2003).

Para aCC, optou-se por se fazer levantamentos primários para a parametrização do solo, parte primordial da modelagem hidrológica com o J2000/JAMS. Para tanto, foram realizadas amostragens de solo em 3 pontos da bacia em três profundidades diferentes (50, 100 e $200 \mathrm{~cm}$ ), tendo sido necessária a abertura de trincheira de aproximadamente $2 \times 2 \times 2 \mathrm{~m}$. As amostras foram do tipo indeformadas para análise da porosidade total e efetiva, da massa específica dos grãos, da densidade do solo e da curva de retenção. Nas mesmas profundidades foram coletadas amostras deformadas para análise de umidade do solo e para teste de peneiramento para traçar as curvas granulométricas

Tabela 1 - Parâmetros das propriedades físicas da bacia para entrada no modelo J2000/JAMS.

\begin{tabular}{|c|c|c|}
\hline Solo & Cobertura vegetal & Hidrogeologia \\
\hline Profundidade & Albedo (\%) & $\begin{array}{c}\text { Capacidade de } \\
\text { armazenamento do aquífero }\end{array}$ \\
\hline $\begin{array}{l}\text { Condutividade } \\
\text { hidráulica }\end{array}$ & Resistência superficial & $\begin{array}{l}\text { Coeficiente de } \\
\text { armazenamento }\end{array}$ \\
\hline $\begin{array}{l}\text { Capacidade } \\
\text { de ar }\end{array}$ & Índice de área foliar & \\
\hline \multirow[t]{2}{*}{$\begin{array}{l}\text { Capacidade de } \\
\text { campo }\end{array}$} & Crescimento efetivo & \\
\hline & Profundidade da raiz & \\
\hline
\end{tabular}


Para as duas bacias hidrográficas, os parâmetros da cobertura vegetal foram obtidos após consulta às obras da literatura brasileira.

\section{Calibração e validação do modelo J2000/JAMS nas bacias pilotos}

A calibração do modelo J2000/JAMS para as áreas BRO e BCC foi realizada aplicando o método manual de tentativa e erro de ajuste dos parâmetros, utilizando dados de vazão diária. O monitoramento das vazões do Ribeirão da Onça vem sendo acompanhado em seção de medição específica desde dezembro de 2007, com medições quinzenais auxiliadas por molinete hidrométrico e medições constantes por meio de um linígrafo, conforme descrito em Maldonado (2009). Já a BCC não conta com estações fluviométricas para a medição de vazão diária. Porém, existe uma estação fluviométrica do DAEE (código-023), coordenadas $22^{\circ} 07^{\prime} 44^{\prime \prime S}$ e $47^{\circ} 40^{\prime} 02^{\prime \prime} \mathrm{W}$, no Rio Corumbataí, localizado próximo à confluência entre esse rio e o Córrego Cavalheiro.

Para a regionalização dos dados de vazão para o Córrego Cavalheiro foi utilizado um método simples de regionalização para uma aplicação de forma mais imediata. A forma mais simples de regionalização hidrológica é o estabelecimento de uma relação linear entre vazão e área de drenagem da bacia (COLLISCHON \& DORNELLES, 2013), utilizando-se a Equação 7.

$Q_{A}=Q_{B} \cdot \frac{A_{A}}{A_{B}}$

onde:

$\mathrm{A}_{\mathrm{A}}$ é a área de drenagem da bacia no ponto $\mathrm{A}$;

$A_{B}$ é a área de drenagem da bacia no ponto $B$;

$\mathrm{Q}_{\mathrm{A}}$ é a vazão média no ponto $\mathrm{A}$; e

$\mathrm{Q}_{\mathrm{B}}$ é a vazão média no ponto $\mathrm{B}$.

A área da BCC no ponto de seu exutório (983 ha) corresponde a $17 \%$ da área da bacia do Rio Corumbataí no ponto da estação do DAEE (5.940 ha).

Esse método pode ser utilizado quando as características das duas bacias são homogêneas quanto às características de relevo, clima, solo, uso do solo e geologia (COLLISCHONN \& DORNELLES, 2013). Devido à proximidade das bacias do Rio Corumbataí no ponto da estação fluviométrica do DAEE e do Córrego Cavalheiro, as características de clima, relevo, solo e geologia das duas áreas de drenagem são bastante semelhantes. Em uma análise de uso do solo, por meio de fotointerpretação de imagem aérea, sobrevoo 2010, constatou-se que a proporção entre as classes de uso do solo também é semelhante.

Para a validação do método de regionalização de vazão adotado, foram realizadas medições de vazão mensais durante oito meses nos dois pontos considerados, com o uso de micromolinete. As vazões medidas revelam que o valor da relação de áreas entre as duas bacias
$(0,17)$ está bem próximo da relação média entre as vazões medidas no Córrego Cavalheiro $(\mathrm{Qb})$ e as medidas no Rio Corumbataí (Qa), que foi de $0,20 \pm 0,02$. Assim, na Equação 7 foi utilizado um fator de correção $n=0,88$, conforme a Equação 8 .

$Q_{A}=Q_{S} \cdot\left(\frac{A_{A}}{A_{B}}\right)^{n}$

Enfim, para a avaliação do comportamento do modelo hidrológico e do seu desempenho para a estimativa da vazão foi realizado um teste de divisão de amostras (Split-sample test, em inglês), proposto por Klemes (1986), que consiste na divisão dos dados de vazão observada, parte para a comparação no período de calibração e parte para o período de validação do modelo calibrado. Para a BRO, o período de calibração selecionado foi de junho de 2008 a junho de 2010, e o período de validação de julho de 2010 a agosto de 2011. Para a BCC, os períodos selecionados foram de janeiro de 2010 a dezembro de 2011 para a calibração e de janeiro de 2012 a dezembro de 2012 para a validação. Para a atenuação do efeito de inicialização dos armazenamentos, um período de aquecimento de três anos de dados, selecionado devido às análises realizadas por Machado, Wendland e Krause (2016), foi utilizado.

Para diminuir a subjetividade da comparação visual entre as curvas de vazão, o desempenho do modelo foi testado por meio de três funções:

1. coeficiente de eficiência de Nash-Sutcliffe (NSE - Equação 9),

2. porcentagem de viés (PBIAS - Equação 10) e

3. raiz do erro quadrático médio (RMSE - Equação 11).

O NSE foi proposto por Nash e Sutcliffe em 1970 e, por isso, é conhecido pelo nome de seus autores. Esse coeficiente vem sendo amplamente utilizado na avaliação estatística do desempenho de modelos hidrológicos (ALE et al., 2012). O NSE é descrito pela Equação 9 (MORIASI et al., 2007).

$N S E=1-\frac{\sum_{i}^{n}\left[Y_{i}^{o b s}-Y_{i}^{\text {sim }}\right]^{2}}{\sum_{i}^{n}\left[Y_{i}^{\text {obs }}-Y_{i}^{\text {med }}\right]^{2}}$

onde:

$Y_{i}^{o b s}$ é a vazão observada;

$Y_{i}^{\text {sim }}$ é a vazão simulada; $\mathrm{e}$

$Y_{i}^{\text {med }}$ é a média da vazão observada.

O NSE varia entre - $\infty$ e 1 . Uma eficiência menor do que 0 indica que a média é um melhor preditor do que o modelo, e uma eficiência ótima tem o valor de 1 (GUPTA et al., 1999).

A porcentagem de viés (PBIAS) mede a tendência de os dados simulados serem menores ou maiores do que os dados observados (GUPTA; SOROOSHIAN; YAPO, 1999). O seu valor ótimo é 0, com valores baixos indicando uma simulação acurada (MORIASI et al., 2007). A equação do PBIAS é descrita pela Equação 10. 
PBIAS $=\left[\frac{\sum_{i=1}^{n}\left(Y_{i}^{s i m}-Y_{i}^{\text {obs }}\right)}{\left.\sum_{i=1}^{n} Y_{i}^{o b s}\right)}\right] \star 100 \quad[\%]$

onde:

PBIAS é a porcentagem de viés;

$Y_{i}^{s i m}$ é a vazão simulada;

$Y_{i}^{\text {obs }}$ é a vazão observada.

Valores positivos de PBIAS indicam que o modelo está superestimando os valores de vazão, enquanto valores negativos indicam que o modelo subestima esses valores.

Uma avaliação proposta por Moriasi et al. (2007) determinou diretrizes para avaliação dos modelos hidrológicos distribuindo os valores dos coeficientes NSE e PBIAS em quatro categorias (insatisfatório; satisfatório; bom; e muito bom), conforme a Tabela 2 .

Esses coeficientes analisam a concordância do modelo com o escoamento superficial observado nas áreas de estudo. Para análise do volume escoado, foi utilizado o valor da RMSE (Equação 11), uma medida bem-aceita do erro absoluto das predições dos modelos (HARMEL \& SMITH, 2007). O menor valor de RMSE indica o melhor ajuste dos valores simulados com os valores observados.

$R M S E=\left[n^{-1} \sum_{i=1}^{n}\left(Y_{i}^{s i m}-Y_{i}^{o b s}\right)^{2}\right]^{0,5} \quad\left[\frac{m^{3}}{s}\right]$

onde:

RMSE é a raiz do erro quadrático médio;

$Y_{i}^{\text {sim }}$ é a vazão simulada;

$Y_{i}^{\text {obs }}$ é a vazão observada.

\section{RESULTADOS E DISCUSSÃO}

\section{Desempenho do modelo J2000}

A qualidade da calibração e validação do modelo foi primeiramente analisada com base na análise visual das curvas de vazão observadas e simuladas pelo modelo, apresentadas na Figura 5. Para ambas as áreas de estudo, os picos, as subidas e as recessões do hidrograma foram

Tabela 2 - Avaliação do desempenho de modelos a partir dos coeficientes de eficiência de Nash-Sutcliffe e porcentagem de viés.

\begin{tabular}{|c|c|c|}
\hline $\begin{array}{l}\text { Avaliação do } \\
\text { desempenho }\end{array}$ & $\begin{array}{l}\text { Coeficiente de eficiên- } \\
\text { cia de Nash-Sutcliffe }\end{array}$ & Porcentagem de viés \\
\hline Muito bom & $0,75<\mathrm{NSE}<1,00$ & $-10<\mathrm{PBI} A S<+10$ \\
\hline Bom & $0,65<N S E \leq 0,75$ & $\begin{array}{c}+10<\text { PBIAS }<+15 \\
\text { ou }-15<\text { PBIAS }<-10\end{array}$ \\
\hline Satisfatório & $0,50<$ NSE $\leq 0,65$ & $\begin{array}{c}+15<\text { PBIAS }<+25 \\
\text { ou }-25<\text { PBIAS }<-15\end{array}$ \\
\hline Insatisfatório & NSE $\leq 0,50$ & PBIAS $>+25$ ou $P B \mid A S<-15$ \\
\hline
\end{tabular}

NSE: coeficiente de eficiência de Nash-Sutcliffe; PBIAS: porcentagem de viés. Fonte: Adaptado de Moriasi et al. (2007). devidamente representados. Pode-se perceber pelos gráficos que os picos dos grandes eventos de chuva, nas duas bacias hidrográficas, foram subestimados pelo modelo. Entretanto, as ascensões e as recessões do hidrograma foram satisfatoriamente representadas. Os valores de vazão na estiagem ficaram bem próximos das vazões observadas, o que garante uma adequada estimativa do escoamento de base.

A análise estatística da calibração e validação do modelo J2000 para a BRO e para a BCC é mostrada na Tabela 3. Segundo Sorooshian e Gupta (1995), uma das desvantagens da calibração manual é a ausência de certeza se o melhor ajuste já foi alcançado, para que o processo seja encerrado. Por isso, a calibração para ambas as áreas de estudo foi realizada até que se chegasse a um valor do coeficiente NSE maior do que 0,75 e $-10 \%<$ PBIAS $<+10 \%$, pois com esses valores o modelo já é considerado muito bom, segundo Moriasi et al. (2007).

Baseando-se no guia de avaliação de modelo proposto por Moriasi et al. (2007), para os valores de NSE e PBIAS, o desempenho do modelo J2000 na BRO foi considerado muito bom para ambos os períodos (calibração e validação) e para o período de calibração da BCC. Para o período de validação da BCC, o desempenho foi considerado satisfatório. Esse desempenho satisfatório do modelo pode ser explicado pelo período de apenas um ano selecionado para a calibração do modelo na BCC, uma vez que os dados não permitiram a escolha de um período maior devido ao método de regionalização de vazão adotado. O desempenho satisfatório foi apenas verificado pelo valor do NSE. A maior desvantagem desse coeficiente está no fato de que a diferença entre os valores observados e previstos é elevada ao quadrado, o que superestima os picos do hidrograma, enquanto os baixos valores são negligenciados (LEGATES \& McCABE Jr, 1999).

O modelo J2000/JAMS subestimou as vazões de pico de grandes eventos de chuva nas duas áreas de estudo, uma razão para isso, citada por Spruill, Workman e Taraba (2000), foi o efeito do ajuste das precipitações — tanto em tempo quanto em magnitude - , regionalizadas a partir de estações climatológicas localizadas fora da área das bacias hidrográficas.

Ressalta-se que, devido à subestimação dos picos do hidrograma para os grandes eventos de chuva, o modelo não poderia ser utilizado para a predição de eventos de inundação/enchentes. Entretanto, o modelo pode ser utilizado para a gestão da disponibilidade hídrica da bacia hidrográfica, uma vez que os valores absolutos de vazão foram corretamente simulados. Conclusão baseada nos baixos valores obtidos para o erro absoluto, calculado com o RMSE (Tabela 3).

\section{Mapas de escoamento}

Uma das razões para a escolha do modelo J2000/JAMS foi devido à sua característica de simulação distribuída do escoamento. Assim, o escoamento é simulado em toda a bacia hidrológica em cada URH. Como resultado, são produzidos mapas que mostram em qual URH o escoamento foi gerado. Outra importante característica do J2000/JAMS que auxilia na simulação de cenários 
de uso e ocupação do solo é que o escoamento é separado entre escoamento direto, interfluxo lateral, interfluxo e escoamento de base. Na Figura 6 é mostrado o mapa gerado pelo J2000/JAMS para o escoamento direto na BRO, no período de 2003 a 2011. Como na bacia não existem áreas efetivamente impermeabilizadas, o escoamento direto na bacia ocorreu apenas durante grandes eventos de chuva.

$\mathrm{Na}$ BCC o escoamento direto foi mais presente (Figura 7), pois na área de estudo localiza-se parte da área urbana de Analândia, São Paulo, no sudoeste da bacia.

Em estudos sobre as relações entre a cobertura florestal e a disponibilidade hídrica, Warbuton, Schulze e Jewitt (2012) concluíram que a geração de escoamento não é proporcional à área relativa de cada uso do solo na bacia hidrográfica, porém, a localização específica de cada classe de uso do solo tem uma interferência direta na geração do escoamento. Assim, os mapas de escoamento produzidos pelo modelo J2000/JAMS são produtos importantes para o planejamento de uso e ocupação do solo de bacias hidrográficas, pois garantem a realização de análise especializada da resposta hidrológica de subunidades dentro da bacia hidrográfica.

Portanto, esse produto poderá apoiar a gestão de áreas prioritárias para recuperação da vegetação nativa, visando ao aumento da disponibilidade hídrica, assunto que será o foco dos próximos estudos sobre a BCC.

Tabela 3 - Valores obtidos para a avaliação estatística dos períodos de calibração e validação da bacia hidrográfica do Ribeirão da Onça e da microbacia do Córrego Cavalheiro.

\begin{tabular}{l|c|c|c|c}
\multirow{2}{*}{ Período } & \multicolumn{2}{|c|}{$\begin{array}{c}\text { Bacia Hidrográfica do } \\
\text { Ribeirão da Onça }\end{array}$} & \multicolumn{2}{c}{$\begin{array}{c}\text { Microbacia do } \\
\text { Córrego Cavalheiro }\end{array}$} \\
\cline { 2 - 5 } & $\begin{array}{c}\text { Calibração } \\
\text { jun/2008 a } \\
\text { jun/2010 }\end{array}$ & $\begin{array}{c}\text { Validação } \\
\text { jul/2010 a } \\
\text { ago/2011 }\end{array}$ & $\begin{array}{c}\text { Calibração } \\
\text { jan/2010 a } \\
\text { dez/2011 }\end{array}$ & $\begin{array}{c}\text { jan/2012 a } \\
\text { dez/2012 }\end{array}$ \\
\hline NSE & 0,76 & 0,81 & 0,76 & 0,56 \\
\hline PBIAS (\%) & $-0,66$ & $-2,80$ & $-3,33$ & 0,90 \\
\hline RMSE $\left(m^{3} \cdot S^{-1}\right)$ & 0,14 & 0,18 & 0,02 & 0,03 \\
\hline
\end{tabular}

NSE: coeficiente de eficiência de Nash-Suitcliffe; PBIAS: porcentagem de viés: RMSE: raiz do erro quadrático médio.

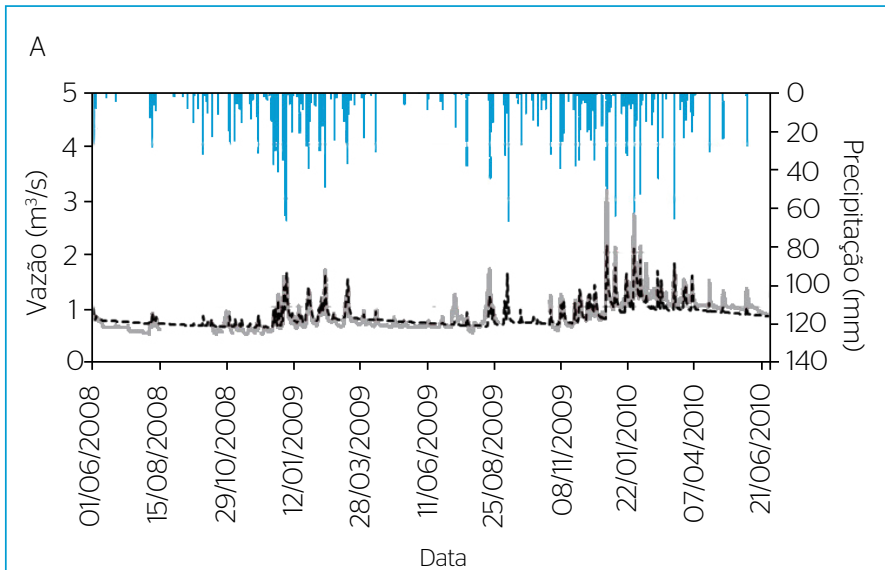

C

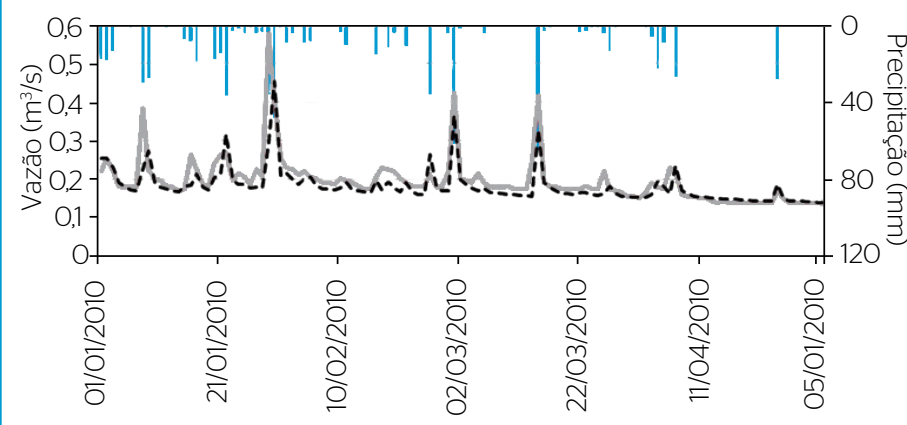

Data
B

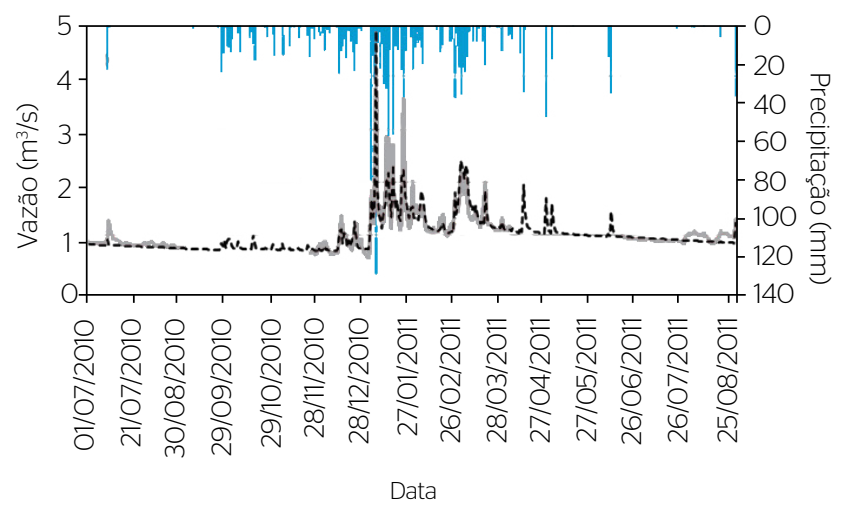

D

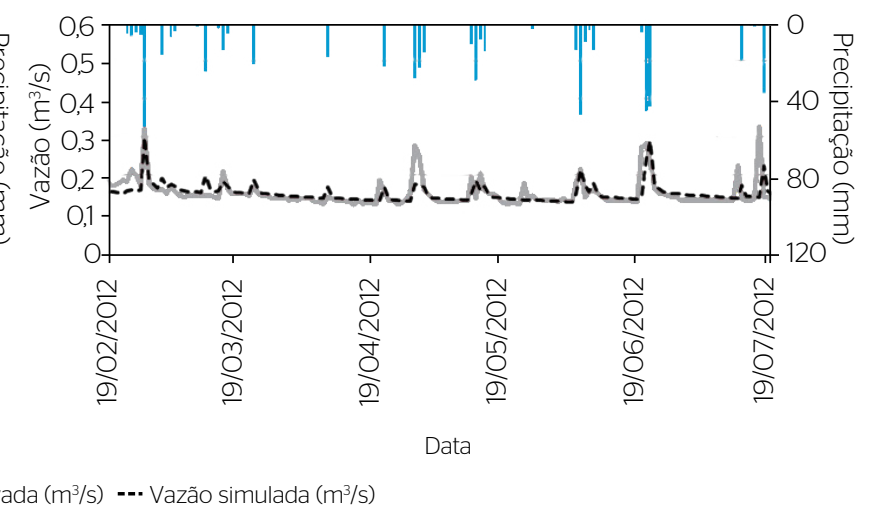

Figura 5 - Gráficos de comparação entre a vazão observada e a vazão simulada pelo modelo J2000/JAMS nos períodos (A) de calibração na Bacia do Ribeirão da Onça; (B) de validação na bacia hidrográfica do Ribeirão da Onça; (C) de calibração na microbacia do Córrego Cavalheiro; (D) de validação na microbacia do Córrego Cavalheiro. 


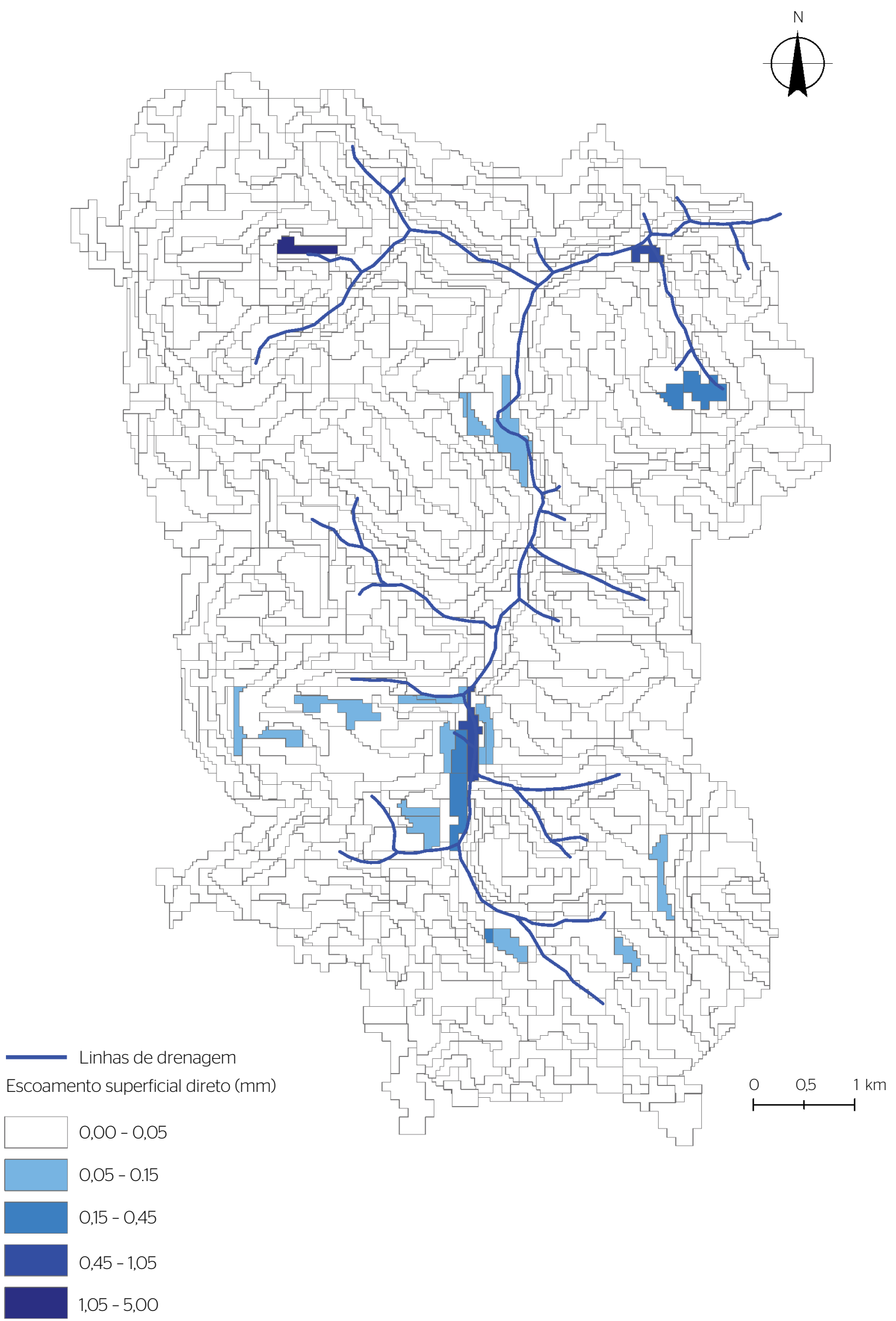

Figura 6 - Distribuição espacial da média de escoamento direto resultado da simulação entre os anos de 2003 e 2011. 


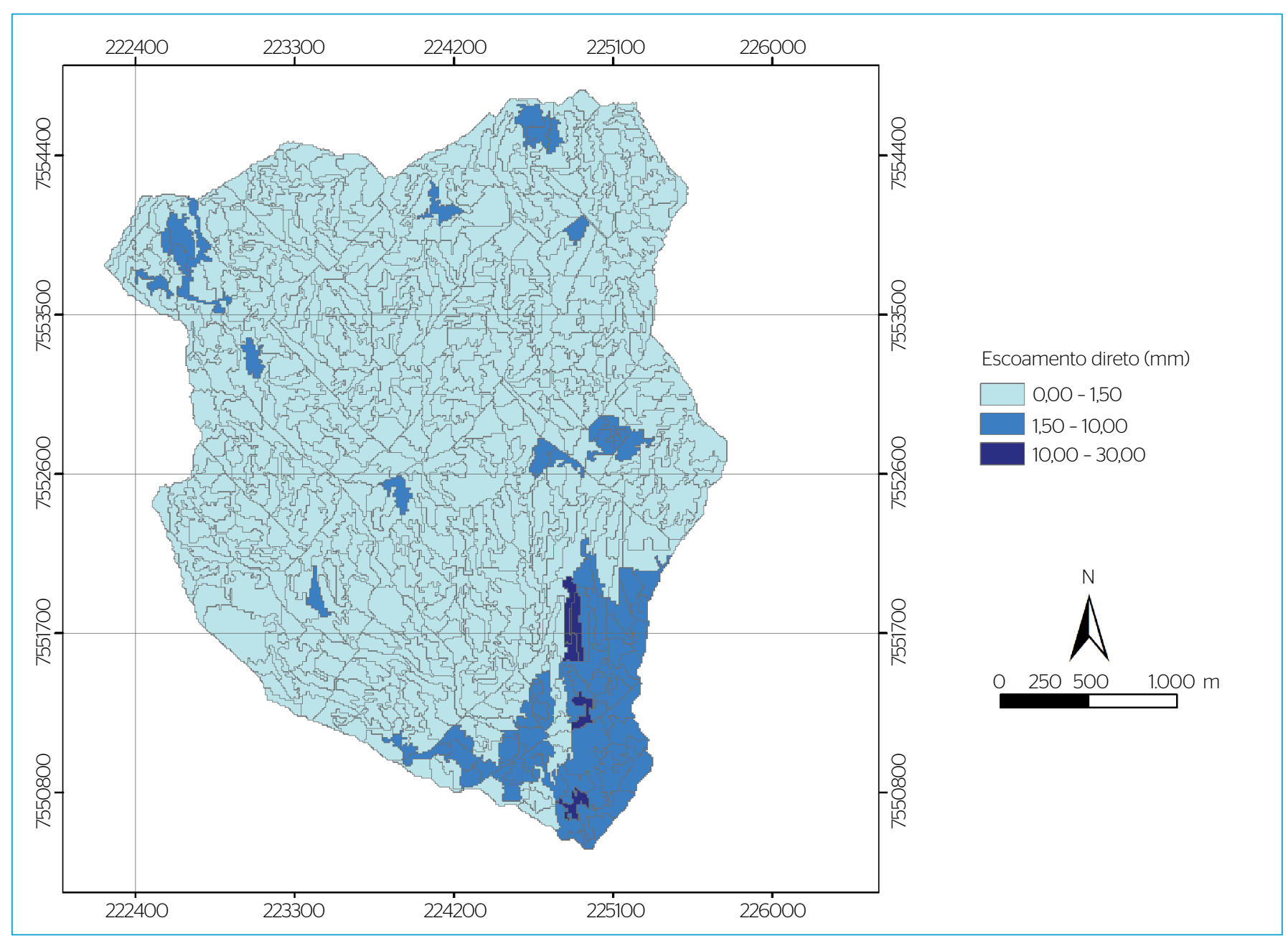

Figura 7 - Distribuição espacial da média de escoamento direto resultado da simulação entre os anos de 2007 e 2012.

\section{CONCLUSÃO}

O sistema framework JAMS não possui literatura específica sobre os seus módulos dos processos hidrológicos; porém, mostrou-se de simples utilização para construção de modelos chuva-vazão, por incluir na sua instalação um modelo exemplo, o J2000. A sua adaptação para a realidade das bacias hidrográficas estudadas foi satisfatória, uma vez que o sistema é flexível às mudanças em sua estrutura. As ferramentas Juice Builder e JADE auxiliam tanto na criação e na modificação dos módulos quanto na execução das simulações e da análise visual dos resultados.

O modelo subdivide a área da bacia hidrográfica em URHs, garantindo a simulação da variabilidade espacial dos processos hidrológicos das bacias hidrográficas, o que pode ser observado pelos mapas de escoamento apresentados ao final da simulação. Foi percebido que o melhor delineamento foi obtido para a BCC, uma vez que o MDE foi elaborado a partir de curvas topográficas de $5 \mathrm{~m}$ de elevação entre cotas.

Para a etapa de parametrização com dados físicos do modelo, os parâmetros foram facilmente conseguidos para a BRO, por essa bacia ter sido objeto de vários estudos. Para bacias hidrográficas com poucos dados, como foi o caso da BCC, é necessário ao menos a amostragem de solo em pontos diversos na bacia, para obtenção dos dados de condutividade hidráulica, profundidade do solo e capacidade de campo, parâmetros importantes para a construção do modelo.

A disponibilidade de dados adequada espacial e temporalmente garantiu uma calibração muito boa para a BRO, apresentando um NSE de 0,76 e 0,81, para os períodos de calibração e validação, respectivamente. Entretanto, apesar da falta de dados de vazão, o que foi superado pela regionalização dos dados fluviométricos, a calibração da BCC foi considerada satisfatória, apresentando um NSE de 0,76 e 0,56, para os períodos de calibração e validação, respectivamente.

O modelo foi capaz de fornecer valores assertivos para a vazão, uma vez que o erro, calculado pelo valor da RMSE, foi considerado baixo por apresentar valores de 0,14 e $0,18 \mathrm{~m}^{3} \cdot \mathrm{s}^{-1}$ para os períodos de calibração e validação da $\mathrm{BRO}$ e de 0,02 e $0,03 \mathrm{~m}^{3} \cdot \mathrm{s}^{-1}$ para os períodos de calibração e validação da BCC. Portanto, 
o J2000/JAMS mostrou-se um candidato potencial para modelagem hidrológica de bacias hidrográficas do Estado de São Paulo, podendo servir como ferramenta de planejamento de uso e ocupação do solo, por ser capaz de produzir mapas com espacialização da geração de escoamento.
A partir das vantagens apresentadas na avaliação do JAMS, existe a expectativa de que outros pesquisadores e gestores utilizem esse sistema para aplicações particulares, melhorando a eficiência da simulação dos modelos criados com a adaptação de outros módulos para as características climatológicas e hidrológicas do Brasil.

\section{REFERÊNCIAS}

ALE, S.; BOWLING, L.C.; OWENS, P.R.; BROUDER, S.M.; FRANKENBERGER, J.R. (2012) Development and application of a distributed modeling approach to assess the watershedscale impact of drainage water management. Agricultural Water Management, v. 107, p. 23-33.

ALLEN, R.G.; PEREIRA. L.S.; RAES. D.; SMITH, M. (1998) Crop evapotranspiration: guidelines for computing crop water requirements. FAO Irrigation and drainage Paper 56. Rome: FAO.

ANDREWS, F.T.; CROKE, B.F.W.; JAKEMAN, A.J. (2011) An open software environment for hydrological model assessment and development Environmental Modelling \& Software, v. 26, n. 10, p. 1171-1185.

ASCOUGH II, J.C.; DAVID, O.; KRAUSE, P.; HEATHMAN, G.C.; KRALISCH S.; LAROSE, M.; AHUJA L.R.; KIPKA, H. (2O12) Development and application of a modular watershed-scale hydrologic model using the object modeling system: runoff response evaluation. Transactions of the American Society of Agricultural Engineers, v. 55, n. 1, p. 117-135.

BAKER, T.J. \& MILLER, S.N. (2013) Using the Soil and Water Assessment Tool (SWAT) to assess land use impact on water resources in an East African watershed. Journal of Hydrology, v. 486, p. 100-111.

BENDE-MICHL. U.; KEMNITZ, D.; HELMSCHROT, J.; KRAUSE, P.; CRESSWELL, H.; KRALISCH, S.; FLÜGEL, W.A. (2007) Supporting natural resources management in Tasmania through spatially distributed solute modelling with JAMS/J2000-S. In: OXLEY, L. \& KULASIRI, D. (Eds.) MODSIM 2007 International Congress on Modelling and Simulation. Canberra: Modelling and Simulation Society of Australia and New Zealand. p. 2354-2360.

BRASIL (1997). Lei Federal no 9.433, de 8 de janeiro de 1997. Institui a Política Nacional de Recursos Hídricos, cria o Sistema Nacional de Gerenciamento de Recursos Hídricos, regulamenta o inciso XIX do art. 21 da Constituição Federal, e altera o art. 10 da Lei no 8.001, de 13 de março de 1990, que modificou a Lei no 7.990, de 28 de dezembro de 1989. Brasília: Diário Oficial da União.

CASTRO JUNIOR, P.R. \& WENDLAND, E.C. (2008) Mapeamento morfopedológico aplicado à bacia-piloto do Ribeirão da Onça (SP) e à bacia-escola do Rio Cachoeirinha (MT) em áreas de recarga do Aqüifero Guarani. Relatório do Programa Nacional de Cooperação Acadêmica - CAPES. São Carlos: USP/EESC (Mapa de Solo).

CAWSON, J.G.; SHERIDAN, G.J.; SMITH, H.G.; LANE, P.N.J. (2012) Surface runoff and erosion after prescribed burning and the effect of different fire regimes in forests and shrublands: a review. International Journal of Wildland Fire, v. 21, n. 7, p. 857-872.

COLLISCHON, W. \& DORNELLES, F. (2013) Hidrologia para engenharias e ciências ambientais. 1 ed. Porto Alegre: Associação Brasileira de Recursos Hídricos. 336 p.

CUNHA, A.T. (2003) Estimativa experimental da taxa de recarga na zona de afloramento do Aquifero Guarani. 118f. Dissertação (Mestrado em Engenharia Hidráulica e Saneamento) - Escola de Engenharia de São Carlos, Universidade de São Paulo, São Carlos.

DICKINSON, R.E. (1984) Modeling evapotranspiration for threedimensional global climate models. In: HANSEN, J.E. \& TAKAHASHI, T. Climate processes and climate sensitivit. Washington: American Geophysical Union.

FENICIA, F.; McDONELL, J.J.; SAVENIJE, H.H.G. (2008) Learning from model improvement: on the contribution of complementary data to process understanding. Water Resources Research, v. 44, n. 6, W06419.

FERRAZ, S.F.B.; LIMA, W.P.; RODRIGUES, C.B. (2013) Managing forest plantation landscapes for water conservation. Forest Ecology and Management, v. 301, p. 58-66.

GOMES, L. H. (2008) Determinação da recarga profunda na bacia piloto do Ribeirão da Onça em zona de afloramento do Sistema Aquífero Guarani a partir de balanço hídrico na zona saturada. 167f. Dissertação (Mestrado em Engenharia Hidráulica e Saneamento) - Escola de Engenharia de São Carlos, Universidade de São Paulo São Carlos.

GUPTA, H.V:; SOROOSHIAN, S.; YAPO, P.O. (1999) Status of automatic calibration for hydrologic models: comparison with multilevel expert calibration. Journal of Hydrologic Engineering, v. 4, n. 2, p. 135-143.

HARMEL, R.D. \& SMITH, P.K. Consideration of measurement uncertainty in the evaluation of goodness-of-fit in hydrologic and water quality modeling. Journal of Hydrology, v. 337, n. 3-4, p. 326-336.

IPT - INSTITUTO DE PESQUISA TECNOLÓGICA DO ESTADO DE SÃO PAULO. (1981) Mapa Geomorfológico do Estado de São Paulo: Nota Explicativa. São Paulo: IPT. 98 p.

KLEMES, V. (1986) Operational testing of hydrological simulation models. Hydrological Sciences Journal, v. 31, n. 1, p. 13-24. 
KRAFT,P.; VACHÉ, K.B.; FREDE, H.G.; BREUER, L. (2O11)CMF:a hydrological programming language extension for integrated catchment models. Environmental Modelling \& Software, v. 26, n. 6, p. 828-830.

KRALISCH, S.; ZANDER, F.; KRAUSE, P. (2009) Coupling the RBIS Environmental Information System and the JAMS Modelling Framework. In: 18th World IMACS/MODSIM Congress, 1, Anais... Cairns: Modelling and Simulation Society of Australia and New Zealand and International Association for Mathematics and Computers in Simulation. p. 902-908.

KRAUSE, P. (2002) Quantifying the impact of land use changes on the water balance of large catchments using the J2000 model. Physics and Chemistry of the Earth, Parts A/B/C, v. 27, n. 9-10, p. 663-673.

KRAUSE, P.; BOYLE, D.P.; BÄSEL, F. (2005). Comparison of different efficiency criteria for hydrological model assessment. Advances in Geosciences, v. 5, p. 89-97.

KRAUSE, P. \& FLÜGEL, W.A. (2005) Integrated research on the hydrological process dynamics from the Wilde Gera catchment in Germany. In: Headwater Control VI: Hydrology, Ecology and Water Resources in Headwaters, Anais... Bergen: IAHS.

KRAUSE, P. \& HANISCH, S. (2009) Simulation and analysis of the impact of projected climate change on the spatially distributed water balance in Thuringia, Germany. Advances in Geosciences, v. 21, p. 33-48.

KRAUSE, P.; BÄSE, F.; BENDE-MICHL, U.; FINK, M.; FLÜGEL, W.; PFENNING, B. (2006) Multiscale investigations in a mesoscale catchment: hydrological modelling in the Gera catchement. Advances in Geosciences, v. 9, p. 53-61.

KRAUSE, P.; BENDE-MICHL, U.; FINK, M.; HELMSCHROT, J. KRALISCH, S.; KÜNNE, A. (2009) Parameter sensitivity analysis of the JAMS/J2OOO-S model to improve water and nutrient transport process simulation: a case study for the Duck catchment in Tasmania. In: 18th World IMACS /MODSIM Congress, 1 Anais... Cairns: Modelling and Simulation Society of Australia and New Zealand and International Association for Mathematics and Computers in Simulation. p. 3179-3186.

LEGATES, D.R. \& McCABE Jr., G.J. (1999) Evaluating the use of "goodness-of-fit" measures in hydrologic and hydroclimatic model validation. Water Resources Research, v. 35, n. 1, p. 233-241.

MACHADO, A.R.; WENDLAND, E.; KRAUSE, P. (2016) Hydrologic simulation for water balance improvement in an outcrop area of the Guarani Aquifer System. Environmental Processes, v. 3, n. 1, p. 19-38.

MALDONADO, L.H. (2009) Validação experimental de metodologias para quantificação contínua de vazão no Ribeirão da Onça. $175 f$. Dissertação (Mestrado em Hidráulica e Saneamento) - Escola de Engenharia de São Carlos, Universidade de São Paulo, São Carlos.

MORIASI, D.N.; ARNOLD, J.G.; VAN LIEW, M.W.; BINGNER, R.L.; HARMEL, R.D.; VEITH, T.L. (2007) Model evaluation guidelines for systematic quantification of accuracy in watershed simulations. Transactions of the American Society of Agricultural and Biological Engineers, v. 50, n. 3, p. 885-900.

NEPAL, S.; KRAUSE, P.; FLÜGEL, W.A.; FINK, M.; FISCHER, C. (2O14) Understanding the hydrological system dynamics of a glaciated alpine catchment in the Himalayan region using the J2000 hydrological model. Hydrological Processes, v. 28, n. 3, p. 1329-1344.

PERROTTA, M.M.; SALVADOR, E.D.; LOPES, R.C.; D’AGOSTINO, L.Z:; PERUFFO, N.; GOMES, S.D.; SACHS, L.L.B.; MEIRA, V.T.; GARCIA, M.G.M.; LACERDA FILHO, J.V. (2005) Mapa Geológico do Estado de São Paulo, escala 1:750.000. Formato: shapefile. Programa Geologia do Brasil - PGM, CPRM, São Paulo. Disponível em: < http:// geobank.sa.cprm.gov.br/> Acesso em: 15 fev. 2011.

PINTON, L.G. (2011) A antropogeomorfologia na bacia do córrego do cavalheiro analândia/sp: uma avaliação da dinâmica do uso da terra e sua adequabilidade a legislação ambiental e a capacidade de uso. Trabalho de Graduação (Bacharelado em Geografia) Universidade Estadual Paulista “Júlio de Mesquita Filho”, Rio Claro.

RÖDIGER, T.; SIEBERT, C.; KRAUSE, P. (2008) Linkage of a finite element flow model with a soil moisture model: challanges under semiarid conditions. American Geophysical Union, Fall Meeting, Abstract \#H12D-06. 6

SCHEFFLER, C.; FLÜGEL, W.; KRAUSE, P. (2005) Effectiveness of C-band scatterometer for hydrological tasks. In: Envisat and ERS Symposium, Procedings... Salzburg: ESA.

SILVA, M.M. (2012) Dinâmica espaço-temporal das áreas variáveis de afluência da bacia do córrego Cavalheiro. 142f. Dissertação (Mestrado em Recursos Florestais) - Universidade de São Paulo, Piracicaba.

SILVA, F.D.S.; PEREIRA FILHO, A.J.; HALLAK, R. (2009). Classificação de sistemas meteorológicos e comparação da precipitação estimada pelo radar e medida pela rede telemétrica na bacia hidrográfica do Alto Tietê. Revista Brasileira de Meteorologia, v. 24 n. 3, p. 292-307.

SOROOSHIAN, S. \& GUPTA, V.K. Model Calibration. In: SINGH, V.P. Computer models of watershed hydrology. Water Resources Publication, 1995.

SPRUILL, C.A.; WORKMAN, S.R.; TARABA, J.L. (2000). Simulation of daily and monthly stream discharge from small watersheds using the SWAT model. Transactions of the American Society of Agricultural Engineers, v. 43, n. 6, p. 1431-1439.

TANIKAWA, D.H. \& MANZIONE, R.L. (2O10) Análise temporal do uso e ocupação do solo em uma bacia hidrográfica em área de recarga do Aquifero Guarani. Relatório Final. Ourinhos: UNESP.

TUCCI, C.E.M. (2001) Modelos hidrológicos. 2 ed. Porto Alegre: Ed. UFRGS/ABRH.

WARBURTON, M.L.; SCHULZE, R.E.; JEWITT, G.P.W. (2O12) Hydrological impacts of land use change in three diverse South African catchments. Journal of Hydrology, v. 414-415, p. 118-135.

WENDLAND, E.; BARRETO, C:; GOMES, L.H. (2007) Water balance in the Guarani Aquifer outcroup zone based on hydrogeologic monitoring. Journal of Hydrology, v. 342, n. 3-4, p. 261-269.

WOLF, A.; LAZAROTTO, P.; BUGMANN, H. (2012) The relative importance of land use and climatic change in the Alpine catchments. Climate Change, v. 111, n. 2, p. 279-300. 